\title{
Epidemiology of conventional cardiovascular risk factors among hypertensive subjects with normal and impaired fasting glucose
}

\author{
A A Akintunde
}

Background. Impaired fasting or glucose tolerance and/or diabetes can occur with hypertension, which theoretically predicts a worse cardiovascular risk profile, and consequently requires intensive cardiovasular risk management.

Objectives. To characterise the frequency of the occurence of conventional cardiovascular risk factors among hypertensive subjects with impaired fasting blood glucose.

Methods. We studied 120 hypertensive subjects and 80 ageand sex-matched normotensive controls. Relevant history, clinical examination, laboratory and other tests were undertaken. Body mass index was determined. Informed consent was obtained from all participants, and ethical approval was obtained.

Results. There was no statistically significant diference between the age and gender of the hypertensive subjects and the controls ( $55.1 \pm 10.83$ v. $54.7 \pm 10.89$ years, $p=0.76$ ). The serum fasting lipids were higher, but not statistically significantly, among the hypertensives than the controls (triglycerides $1.23 \pm 0.50 \mathrm{v} .1 .22 \pm 0.48$, $p=0.900$; total cholesterol $4.51 \pm 1.52$ v. $4.38 \pm 0.84, p=0.842$; LDL
$2.51 \pm 1.41$ v. $2.4 \pm 0.63, p=0.811$, respectively). The prevalence of impaired glucose tolerance among newly presenting hypertensive subjects was $30.0 \%$. Hypertriglyceridaemia ( $38.9 \%$ v. $6.0 \%, p=0.038$ ), hypo-HDL cholesterolaemia $(52.7 \%$ v. $31.0 \%, p=0.028)$ and visceral obesity $(52.8 \%$ v. $27.4 \%, p=0.036)$ were statistically more prevalent among hypertensive subjects with impaired glucose tolerance than among those with normal glucose tolerance.

Conclusion. The prevalence of impaired glucose tolerance among newly presenting hypertensive subjects is very high, and they have more clusters of cardiovascular risks than those without impaired glucose tolerance. The former therefore need intensive cardiovascular assessment and appropriate preventive and treatment modalities. Glucose parameters of newly presenting hypertensive subjects must be determined to evaluate their cardiovascular risk profile.

S Afr Med J 2010; 100: 594-597.
The prevalence of cardiovascular disease is continuously rising throughout Africa. ${ }^{1-5}$ The epidemiological transition impelling the developing world towards more non-communicable diseases, and especially cardiovascular disease, has been attributed to westernisation, reduced physical activity, obesity and the growing prevalence of cardiovascular risk factors. ${ }^{1}$ Although the prevalence of cardiovascular diseases is at present less than in the developed world, an enormous rise in the near future, and also that most of the increase will come from developing nations (especially Africa), has been predicted. ${ }^{6}$ The African INTERHEART Study, ${ }^{7}$ which looked at the contribution of conventional risk factors among subjects with developed coronary heart disease (CHD), found that $90 \%$ of these subjects had the conventional risk factors of smoking, diabetes mellitus (DM), hypertension, abdominal obesity and dyslipidaemia. This finding further highlights a similar pathway in the evolution of cardiovascular diseases.

Hypertension and diabetes are related to one another in many ways. Both can individually and jointly increase cardiovascular risk, morbidity and mortality of individual subjects. ${ }^{5}$ Heart disease (especially CHD) is a major cause of morbidity and mortality among subjects with abnormal glucose tolerance. ${ }^{9}$ The National Cholesterol Education Programme Adult Treatment Panel III views diabetes as

Division of Cardiology, Ladoke Akintola University Teaching Hospital (LAUTECH), Osogbo, Osun State, Nigeria

A A Akintunde, MB ChB, FWACP being a cardiovascular risk factor equivalent to hypertension. ${ }^{10}$

It has been suggested that impaired glucose tolerance develops slowly among hypertensive subjects. ${ }^{11}$ There are few reports on the pattern of CHD risk factors among hypertensive subjects with impaired glucose tolerance in Africa. However, studies have shown that impaired glucose tolerance is more prevalent among hypertensive subjects than normotensive subjects. ${ }^{11,12}$

We studied the epidemiology of conventional CHD risk factors among hypertensive subjects with abnormal fasting glucose and those with normal fasting glucose.

\section{Material and methods}

One hundred and twenty consecutive newly presenting subjects with systemic hypertension were recruited from the Cardiology Clinic of Ladoke Akintola University Teaching Hospital (LAUTECH) in Osogbo, Nigeria. Hypertension was diagnosed when blood pressure was persistently $\geq 140 / 90 \mathrm{mmHg}$. The investigators took blood pressures using standardised protocols. ${ }^{13}$ Eighty age- and sexmatched normotensive subjects who were not previously diagnosed hypertensive subjects and whose blood pressures were persistently $\geq 140 / 90 \mathrm{mmHg}$ were recruited among hospital staff and patients' relatives after informed consent was obtained.

Each subject had a relevant clinical history taken, including demographic parameters, age, gender, occupation, past history of hypertension and DM, smoking history, alcohol intake, and family history of hypertension and diabetes. Past history of early morning facial puffiness, frothiness of urine or passage of smoky urine was taken to rule out renal causes of secondary hypertension. Other causes of secondary hypertension were ruled out by appropriate history, and any suspected case was subsequently excluded. All the subjects had urinalysis and renal ultrasound.

Weight to the nearest $0.5 \mathrm{~kg}$ was taken by a standard weighing scale with the subjects in light clothing. Waist circumference was taken at the midpoint between the lowest rib and the anterior 
superior illiac spine. Hip circumference was taken over the greater trochanters. The waist/hip ratio (WHR) was determined. Height was taken with a stadiometer. Body mass index (BMI) $\left(\mathrm{kg} / \mathrm{m}^{2}\right)$ was defined as weight $/\left(\right.$ height $\left.^{2}\right)$. Obesity was defined as BMI $>30$ and/ or waist circumference $>102 \mathrm{~cm}$ for men and $>88 \mathrm{~cm}$ for women. A fasting serum lipid was also done to estimate the fasting serum total cholesterol, triglycerides, low-density lipoprotein (LDL) and highdensity lipoprotein (HDL). Low HDL was defined as $<1.3 \mathrm{mmol} / \mathrm{l}$ for females and $<1.03 \mathrm{mmol} / \mathrm{l}$ for males. Hypertriglyceridaemia was defined as triglycerides $>1.7 \mathrm{mmol} / \mathrm{l}$, and total cholesterol was considered high if $>6.1 \mathrm{mmol} / \mathrm{l}$. Fasting blood sugar was done using the glucose oxidase method after at least an 8-hour fast. Abnormal glucose tolerance was defined as fasting blood sugar $\geq 5.5 \mathrm{mmol} / \mathrm{l}$ according to the International Diabetes Federation criteria. ${ }^{14}$ Ethical clearance was obtained for the study.

Data were analysed using Statistical Package for Social Sciences (SPSS) 16.0 (Chicago, Ill.). Quantitative data were summarised as means $\pm \mathrm{SD}$, while qualitative data were summarised as frequency and percentages. Student's $t$-test and the chi-square test were used appropriately. Statistical significance was taken as $p<0.05$.

\section{Results}

The clinical characteristics of the study participants are as shown in Table I. Mean waist circumference, BMI, fasting blood glucose and waist/hip ratio were significantly higher among hypertensive subjects than normotensive controls. The distribution of major cardiovascular risk factor among hypertensive subjects with normal fasting glucose and those with impaired fasting glucose is shown in Table II. Hypertriglyceridaemia, low HDL, hyperchlesterolaemia and elevated LDL were significantly higher among hypertensive subjects with impaired fasting glucose than among hypertensive subjects with normal fasting glucose. Furthermore, hypertensive subjects with impaired fasting glucose had higher mean waist circumferences than those with normal fasting glucose, as shown in Table III. Other clinical characteristics were similar between these two groups.

\section{Discussion}

The frequency of occurence of impaired fasting glucose in the present study was $30.0 \%$; this is a high figure and reinforces the interrelationship between hypertension, progresive insulin resistance and the development of DM, a finding that agrees with similar reports by Essien et al. ${ }^{11}$ who subjected hypertensive subjects to oral glucose tolerance tests and reported that $32.8 \%$ of them had impaired glucose tolerance. In this and other studies, ${ }^{15}$ the basal blood glucose level was higher among hypertensive subjects than control subjects. It has also been shown that simple clinical parameters such as BMI, fasting glucose, and insulin levels can be used to predict the prescence of hyperinsulinaemia among hypertensive subjects. These tests may therefore be used to predict progression of abnormal glucose tolerance. $^{15}$

The relationship between hypertension and diabetes is complex. Hypertension is considerably more prevalent in diabetic patients than in nondiabetics. ${ }^{16,17}$ Hypertensive patients are 2.5 times more likely to develop type 2 diabetes than their normotensive counterparts when matched to age, sex, ethnicity, adiposity, level of physical activity and family history. ${ }^{17,18}$ Suggested causes for the increased tendency to develop DM include altered insulin sensitivity of skeletal muscle tissue and reduced blood flow to skeletal muscle tissue owing to vascular hypertrophy, rarefaction and vasoconstriction. ${ }^{16,19}$

Impaired fasting glucose (IFG) and impaired glucose tolerance (IGT) are strong predictors of type $2 \mathrm{DM}$, cardiovascular diseases and other complications of DM. ${ }^{20,21}$ The Strong Heart Study has also shown that IFG and IGT are associated with a greatly increased risk of cardiovascular disease even in prehypertensive individuals. ${ }^{22}$ Therefore, to identify high-risk individuals early, the glucose blood profile of hypertensive subjects should always be taken. ${ }^{23,24}$

Table I. Clinical characteristics of the study population

\begin{tabular}{|c|c|c|c|}
\hline Parameter & Hypertensives $(N=120)$ & Controls $(N=80)$ & $p$-value \\
\hline Age (years) & $55.1 \pm 10.83$ & $54.7 \pm 10.89$ & 0.76 \\
\hline \multicolumn{4}{|l|}{ Gender } \\
\hline Male (\%) & $66(55.0 \%)$ & $47(58.8 \%)$ & \\
\hline Female (\%) & $54(45.0 \%)$ & $35(41.2 \%)$ & 0.822 \\
\hline SBP (mmHg) & $147.72 \pm 26.47$ & $115.1 \pm 13.2$ & $<0.001^{\star}$ \\
\hline $\mathrm{DBP}(\mathrm{mmHg})$ & $89.3 \pm 17.0$ & $70.96 \pm 9.7$ & $<0.001^{\star}$ \\
\hline No. of smokers(\%) & $12(10.0 \%)$ & $1(1.25 \%)$ & $0.0023^{*}$ \\
\hline \multicolumn{4}{|l|}{ Waist $(\mathrm{cm})$} \\
\hline Male & $93.72 \pm 12.64$ & $84.1 \pm 6.93$ & \\
\hline Female & $93.99 \pm 11.55$ & $83.6 \pm 10.6$ & $<0.001^{\star}$ \\
\hline $\mathrm{TC}(\mathrm{mmol} / \mathrm{l})$ & $4.51 \pm 1.52$ & $4.38 \pm 0.84$ & 0.847 \\
\hline BMI $\left(\mathrm{kg} / \mathrm{m}^{2}\right)$ & $26.9 \pm 5.31$ & $23.9 \pm 3.5$ & $<0.001^{*}$ \\
\hline $\mathrm{LDL}(\mathrm{mmol} / \mathrm{l})$ & $2.5 \pm 1.41$ & $2.4 \pm 0.63$ & 0.811 \\
\hline Triglycerides (mmol/l) & $1.23 \pm 0.50$ & $1.22 \pm 0.48$ & 0.900 \\
\hline \multicolumn{4}{|l|}{$\mathrm{HDL}(\mathrm{mmol} / \mathrm{l})$} \\
\hline Male & $1.16 \pm 0.45$ & $1.28 \pm 0.37$ & \\
\hline Female & $1.25 \pm 0.49$ & $1.18 \pm 0.47$ & 0.642 \\
\hline $\mathrm{FBS}(\mathrm{mmol} / \mathrm{l})$ & $5.6 \pm 1.93$ & $3.98 \pm 1.29$ & $0.000^{*}$ \\
\hline PP (mmHg) & $57.93 \pm 24.84$ & $44.76 \pm 10.25$ & $0.000^{*}$ \\
\hline \multicolumn{4}{|l|}{ WHR } \\
\hline Male & $0.97 \pm 0.07$ & $0.92 \pm 0.05$ & \\
\hline Female & $0.92 \pm 0.08$ & $0.89 \pm 0.05$ & $0.01^{*}$ \\
\hline
\end{tabular}




\section{Table II. Distribution of major cardiovascular risk factors among hypertensive subjects with normal and impaired glucose tolerance}

\begin{tabular}{llll}
\hline & Hypertensives with & Hypertensives with \\
NFG $(N=84)$ & IFG $(N=36)$ & N $(\%)$ & $p$-value \\
\hline Parameter & $N(\%)$ & $14(38.9 \%)$ & $0.038^{*}$ \\
Hypertriglyceridaemia & $5(6.0 \%)$ & $5(13.9 \%)$ & 0.432 \\
Cigarette smoking & $7(8.3 \%)$ & $19(52.7 \%)$ & $0.028^{*}$ \\
Low HDL & $26(31.0 \%)$ & $3(8.3 \%)$ & 0.894 \\
Family Hx of DM & $4(4.8 \%)$ & $13(36.1 \%)$ & 0.798 \\
Family Hx of HTN & $21(25 \%)$ & $12(33.3 \%)$ & 0.463 \\
BMI>30kg/m & $15(17.9 \%)$ & $19(52.8 \%)$ & 0.036 \\
Visceral obesity & $23(27.4 \%)$ & $18(50 \%)$ & $0.019^{*}$ \\
Elevated cholesterol & $12(14.3 \%)$ & $10(27.8 \%)$ & $0.034^{*}$ \\
High LDL level & $7(8.3 \%)$ & & \\
*Statistically significant. & & & \\
HDL = high -density lipoprotein; DM = diabetes mellitus; HTN = hypertension; BMI = body mass index; LDL = low-density lipoprotein. & \\
\hline
\end{tabular}

Table III. Clinical characteristics of hypertensive subjects with normal and impaired fasting glucose

\begin{tabular}{llll}
\hline & $\begin{array}{l}\text { Hypertensives with } \\
\text { NFG }(N=84)\end{array}$ & $\begin{array}{l}\text { Hypertensives with } \\
\text { IFG }(N=36)\end{array}$ & $p$-value \\
\hline Age $($ years $)$ & $56.03 \pm 10.7$ & $57.37 \pm 9.43$ & 0.101 \\
BMI $\left(\mathrm{kg} / \mathrm{m}^{2}\right)$ & $27.08 \pm 4.96$ & $27.17 \pm 5.7$ & 0.268 \\
Pulse pressure (mmHg) & $59.28 \pm 18.71$ & $54.78 \pm 16.61$ & 0.366 \\
Waist/hip ratio & $0.95 \pm 0.08$ & $0.94 \pm 0.08$ & 0.195 \\
Waist circumference (cm) & $94.29 \pm 11.95$ & $96.45 \pm 12.41$ & 0.011 \\
Systolic blood pressure $(\mathrm{mmHg})$ & $146.80 \pm 22.31$ & $140.50 \pm 26.29$ & 0.356 \\
Diastolic blood pressure (mmHg) & $87.52 \pm 16.41$ & $87.2 \pm 17.74$ & 0.995 \\
*Statistically significant. & & & \\
NFG = normal fasting glucose; IFG = impaired fasting glucose & & \\
\hline
\end{tabular}

The mean fasting lipid levels in this study were not statistically different among the hypertensive and normotensive subjects, although the hypertensive subjects tended to have a higher level of LDL, triglycerides and total cholesterol, and a lower level of HDL. Other authors have documented similar results among hypertensive subjects and normotensive counterparts. ${ }^{25}$ However, the proportion of smokers was statistically significantly higher among the hypertensive subjects. Comparing the hypertensive subjects with normal fasting glucose with those with impaired fasting glucose, the latter tended to have higher rates of hypertriglyceridaemia, hypoHDL-cholesterolaemia, elevated LDL, hypercholesterolaemia and visceral obesity than those who had normal fasting glucose (Table II). An association between visceral obesity, dyslipidaemia and hypertension has been described..$^{26,27}$

Comparing clinical characteristics between the above two groups, visceral obesity as assessed by waist circumference was the only statistically significant demographic parameter contributing to the presence of impaired fasting glucose. Though subjects with impaired glucosetolerancewereolder, thisstudydoes not confirm the contribution of age to the presence of impaired glucose tolerance among hypertensive subjects. Other workers have documented increased prevalence of cardiovascular risk factors among hypertensive subjects. ${ }^{728-30}$ The present study therefore suggests that hypertensive subjects with impaired fasting glucose may be at an increased cardiovascular risk owing to the tendency for more clustering among them of the major cardiovascular risk factors. Longitudinal studies are therefore necessary to document the pattern of cardiovascular morbidity and mortality of these patients.
The study has some limitations. Firstly, it is hospital-based and may not truly respresent the population at large. Secondly, being a crosssectional study by design, it cannot associate causal relationships between the factors under study.

\section{Conclusion}

Hypertensive subjects with impaired glucose tolerance have a higher chance than those with normal fasting glucose of having many more of the other conventional cardiovascular risk factors. Hypertriglyceridaemia, hypercholesterolaemia, elevated LDL, visceral obesity and low HDL were more common among them than hypertensive subjects with normal fasting glucose. Prospective longitudinal studies are suggested to identify the associated pattern of cardiovascular risk among this population.

\section{References}

1. Vorster $\mathrm{H}$. The emergence of cardiovascular diseases during urbanization of Africans. Publ Health Nutr 2002; 5(1A): 239-243.

2. Yusuf S, Reddy S, Dompao S, et al. Global burden of cardiovascular disease Part I. General considerations, the epidemiologic transition, risk factor and impact of urbanization. Circulation 2001; 104: 2746-2753.

3. Loock M, Steyn K, Becker P, Fourie J. Coronary heart disease and risk factors in Black South Africans: a case control study. Ethn Dis 2006; 16(4): 872-879.

4. Sani MU, Adamu B, Mijinyawa MS, et al. Ischaemic heart disease in Aminu Kano University Teaching Hospital, Kano, Nigeria: A five-year review. Nig J Med 2006; 15(2): 128-131. 
5. Danbauchi SS. Ischaemic heart disease and myocardial infarction in Ahmadu Bello University Teaching Hospital, Zaria, Nigeria: A 10-year review, 1985-1994. A short report. Centr Afr J Med 1996; 42(7): 209-211.

6. Kadiri S. Tackling cardiovascular disease in Africa. BMJ 2005; 331: 711-712.

7. Steyn K, Sliwa K, Hawken S, et al. The INTERHEART investigators in Africa. Risk factors associated with myocardial infarction in Africa: The INTERHEART Africa Study. Circulation 2005; 112(23): 3536-3540.

8. Sowers JR, Epstein M, Frohlich ED. Diabetes, hypertension, and cardiovascular disease: An update. Hypertension 2001; 37: 1053.

9. Blendea MC, McFarlane SI, Isenovic ER, Gick G, Sowes JR. Heart diseases in diabetic patients. Curr Diabet Rep 2003; 3: 223-229.

10. NCEP expert panel on detection, evaluation and treatment of high blood cholesterol in adults: Executive summary of the Third Report of the National Cholesterol Education Program (NCEP) expert panel on detection, evaluation and treatment of high blood cholesterol in adults (Adult Treatment Panel III). JAMA 2001; 285: 2486-2497.

11. Essien OE, Peters EJ, Udoh AE, Ekott JU, Odigwe CO. Prevalence and pattern of abnormal glucose tolerance in Adult Nigerians with primary hypertension. Nig J Med 2007; 16(1): 50-56.

12. Obasohan AO, Enabulele JEE, Okokhere PO, Erhunmwunse RU. Abnormal glucose tolerance in 'early' hypertension in Nigeria. Trop Cardiol 1997; 25(90): $45-49$.

13. Pickering TG, Hall JE, Appel LJ, et al. Recommendations for blood pressure measurement in humans and experimental animals: Part 1: Blood pressure measurement in humans: A statement for professionals from the subcommittee of professional and public education of the American Heart Association Council on High Blood Pressure Research. Hypertension 2005; 45(1): 142-161.

14. International Diabetes Federation. The IDF Consensus Worldwide Definition of the Metabolic Syndrome. Brussels: International Diabetes Federation, 2004. http://www.idf.org (accessed 15 June 2007).

15. Vanhala MJ, Pitkajarin TK, Keinam-Kiukaanniem SM, Kumpusalo EA, TAkala JK. Hyperinsulinaemia in hypertensive subjects: validity of a test for the detection of insulin resistance in clinical practice. J Hum Hypertens 1998; 12(7): 463-467.

16. Bakris GL, Williams M, Dworkin L, et al. Preserving renal function in adults with hypertension and diabetes: A consensus approach. National Kidney Foundation Hypertension and Diabetes Executive Committees Working Group. Am J Kidney Dis 2000; 36: 646-661.

17. McFarlane SI, Banerji M, Sowers JR. Insulin resistance and cardiovascular disease. J Clin Endocrinol Metab 2001; 86: 713-718.
18. Gress TW, Nieto FJ, Shahar E, Wofford MR, Brancati FL. Hypertension and antihypertensive therapy as risk factors for type 2 diabetes mellitus. Atherosclerosis Risk in Communities Study. N Engl J Med 2000; 342 : 9.

19. Sowers JR, Bakris GL. Antihypertensive therapy and the risk of type 2 diabetes mellitus. N Engl J Med 2000; 342: 969-970.

20. Bokyo EJ, Fujimoto NY, Leonetti DL, Newell-Morris L. Visceral adiposity and risk of type 2 diabetes mellitus: A prospective study among Japanese Americans. Diabetes Care 2000; 23: 465-471.

21. DECODE Study group. Glucose tolerance and cardiovascular mortality: Comparison of fasting and 2-hour diagnostic criteria. Arch Int Med 2001; 168 : 397-404.

22. Zhang Y, Lee ET, Devereux RB, et al. Prehypertensive, diabetic and cardiovascular disease risk in a population-based sample. The Strong Heart Study. Hypertension 2006; 19: 189-196.

23. Christ M, Klima T, Maisch B. Arterial hypertension and metabolic syndrome Herz 2003; 28: 674-685.

24. Saad MF, Rewers M, Selby J, et al. Insulin resistance and hypertension: The Insulin Resistance Atherosclerosis Study. Hypertension 2004; 42: 1324-1331.

25. Kesteloot H, Oviasu VO, Obasohan AO, Olomu A, Cobbaert C, Lissens W. Serum lipid and apolipoprotein levels in a Nigerian population sample. Atherosclerosis 1989; 78(1): 33-38.

26. McGarry JD. Banting Lecture 2001: Dysregulation of fatty acid metabolism in the aetiology of type 2 diabetes. Diabetes Care 2002; 51: 7-18.

27. Felber JP, Golay A. Pathways from obesity to diabetes. Int J Obes Relat Metab Disord 2002; 26(suppl. 12): S39-S45.

28. Opadijo OG, Akande AA, Jimoh AK. Prevalence of coronary heart disease risk factors in Nigerians with systemic hypertension. Afr J Med Sci 2004; 33(2): 121125.

29. Lawoyin TO, Asuzu MC, Kaufmann J, et al. Prevalence of cardiovascular risk factors in an African urban inner city community. West Afr J Med 2002; 21(3): 208-211.

30. Salako BL, Ogah OS, Adebiyi AA, et al. Unexpectedly high prevalence of target organ damage in newly diagnosed Nigerians with hypertension. Cardiovasc J Afr 2007; 18(2): 77-83.

Accepted 9 June 2010. 